\title{
INTERPRETANDO A INTERPRETAÇÃO? UMA ANÁLISE DA RACIONALIDADE JURÍDICA DAS SENTENÇAS PROFERIDAS NOS CASOS SOBRE PROPRIEDADE COMUNAL DA CORTE INTERAMERICANA DE DIREITOS HUMANOS. \\ INTERPRETING THE INTERPRETATION? AN ANALYSIS OF THE LEGAL RATIONALITY JUDGMENTS DELIVERED IN CASES OF COMMON PROPERTY OF INTER-AMERICAN COURT OF HUMAN RIGHTS.
}

${ }^{1}$ Rafaela Teixeira Sena Neves

\section{RESUMO}

A partir dos casos da Corte Interamericana de Direitos Humanos que versem sobre propriedade comunal, o presente trabalho visa analisar a racionalidade jurídica utilizada pelos juízes, a fim de compreender a tipo de interpretação dada à Convenção Americana de Direitos Humanos nos referidos casos.

Palavras-chave: Corte interamericana de direitos humanos, Propriedade comunal, Interpretação, Convenção americana de direitos humanos

\begin{abstract}
From the cases of the Inter-American Court of Human Rights that deal with communal property, this paper aims to analyze the legal rationale used by the judges in order to understand the kind of interpretation of the American Convention on Human Rights in these cases.
\end{abstract}

Keywords: Keywords: inter-american court of human rights, Communal property, Interpretation, American convention on human rights

\footnotetext{
${ }^{1}$ Doutoranda em Direito pela Universidade Federal do Pará - UFPA, Pará (Brasil). Professora pela Universidade Federal do Pará - UFPA, Pará (Brasil). E-mail: rafaelatneves@ gmail.com
} 


\section{INTRODUÇÃO}

O estudo dos sistemas regionais de proteção dos Direitos Humanos revela-se um dos campos mais férteis para a análise do caráter evolutivo (e construtivo) do direito internacional dos Direitos Humanos, pois desenvolve interpretações judiciais a partir de parâmetros principiológicos que não se esgotam na mera transcrição literal dos Tratados Internacionais, mas em uma aplicação para além do texto, a qual, diante das nefastas violações, ouve a voz das vítimas por objetivar uma proteção pró-homine mais concreta e eficaz.

Daí porque, a análise dessa interpretação deve ser feita para além da jurisprudência (e até mesmo de um único caso) da Corte Interamericana de Direitos Humanos (CorteIDH ou Corte), ou seja, deve ser realizada a partir de teóricos da Fiolosofia do Direito a fim de se compreender a racionalidade jurídica que pode ser extraída dessas interpretações.

Sendo assim, o estudo visado neste trabalho científico possui o fito de analisar a interpretação dada à Convenção Americana de Direitos Humanos pelos juízes da CorteIDH nas sentenças que se referem a casos sobre propriedade comunal, a fim de compreender a racionalidade jurídica dessa interpretação nesses casos.

E para isso, este trabalho se dividirá didaticamente em (1) uma breve dissertação sobre o direito e a interpretação dos juízes; (2) uma descrição sobre o funcionamento do SIDH; (3) numa análise do entendimento da CorteIDH sobre o direito de propriedade e, em especial, acerca do termo "propriedade comunal"; e (4) nos comentários acerca da coerência do tipo de interpretação utilizada pelos juízes da CorteIDH em atenção à finalidade deste tribunal como um órgão jurisdicional protetor de Direitos Humanos.

Nesse sentido, e para fins didáticos, a metodologia utilizada será a análise da interpretação a partir de casos do próprio SIDH e, para a escolha desses casos, foi levado em consideração dois requisitos: (I) casos de demandas complexas, daí a escolha de casos em que a violação à propriedade comunal é o direito "chave" do qual, todos os outros direitos violados decorrem e (II) casos efetivamente sentenciados pela CorteIDH.

\section{PORQUE INTERPRETAR A INTERPRETAÇÃO?}

Para que a ciência jurídica seja mesmo uma ciência, depende, essencialmente, se o método jurídico cumpre as exigências da cientificidade. A teoria positivista do direito respondia positivamente à questão. $\mathrm{O}$ método jurídico seria científico enquanto subsunção lógica de um caso à lei. 
Tal noção impregnou e ainda impregna a jurisprudência que se entregou ao pensamento de dedução em sistemas fechados, considerado científico em si próprio. O juiz vinculava-se unicamente à fiel letra da lei, não sendo um órgão dotado de vontade própria (KAUFMANN, 2004, p.89).

Hoje, essa concepção encontra-se em vias de ultrapassagem, pois se derrubou o dogma da plenitude e da ausência de lacunas na ordem jurídica, atribuindo-se ao juiz a tarefa criativa no preenchimento de lacunas. Porém, ainda são poucos os que se posicionam de forma positiva ante essa constatação, por defenderem que aos juízes é preferível se vincular à letra estrita e nua da lei, em vez de assumir riscos e responsabilidades que permitam suas atuações em um sistema aberto.

Kaufmann entende que todos os juízes e todo o compreender baseiam-se em précompreensões. Só que elas têm que ser expressas, refletidas e incluídas na argumentação. Os juízos pessoais, para além dos juízos legais, também fazem parte da argumentação. O autor expõe que fundamentos decisórios ocultos são um obstáculo à ciência e à investigação (KAUFMANN, 2004, p.93).

Nessa linha de raciocínio, Michael Moore explica que o modelo comunicativo de interpretação se assemelha ao uso mais usual da noção sobre "interpretação" que é algo que o autor tenta rechaçar. Para ele, esse modelo comunicativo é restrito e não demonstra a riqueza da interpretação (MOORE, 2004, p.04).

Tal modelo diz respeito ao encontrar o significado de algo, e isso leva e faz com que os interlocutores se tornem público de uma elocução comunicativa de outrem, isto é, acabam por buscar as intenções autorais como medida de interpretação, pois as razões e métodos são, em verdade, razões e métodos padronizados da descrição ou explanação científica, com a diferença de que aquilo que se descreve e aquilo com que se explica são ambos fenômenos intencionais.

Para Moore é a partir da noção de hermenêutica que se percebe como esse modelo de interpretação é restrito pelo discernimento de que existe algo especialmente interpretativo em disciplinas como teologia, crítica literária, direito e psicanálise que são áreas certas em que atividades dominantes não se conformam com os métodos meramente descritivos e explanativos das ciências comuns e tampouco as atividades são justificadas pelos objetivos científicos normais de previsão, explanação e compreensão (MOORE, 2004, p.10).

Moore distingue as atividades dos defensores perante juízes, de teóricos que aconselham juízes sobre como julgar. Para ele, os advogados que argumentam perante juízes devem, sem dúvidas, dedicar-se ao raciocínio jurídico interpretativo para persuadir que o próprio juiz o percorra para que chegar a um resultado favorável ao cliente (MOORE, 2004, p.20). 
Entretanto, aconselhar juízes sobre como julgar, isto é, a tarefa dos teóricos do direito não se equipara à advocacia. Quando os teóricos jurídicos aconselham os juízes sobre como interpretar as leis, eles não estão interpretando as leis. O foco são as práticas interpretativas dos juízes, e não as leis interpretadas, de modo que nem os teóricos, nem os juízes estivessem vinculados à tradição americana de ter de seguir "a vontade do legislador" (MOORE, 2004, p.21).

Daí porque, nenhum teórico jurídico deseja pensar em sua atividade teórica como uma atividade interpretativa. Apenas quando os teóricos jurídicos se tornam defensores de interpretações particulares, apenas quando advogados atuam como juízes é que exercem o raciocínio interpretativo (MOORE, 2004, p.40).

Ocorre que, em se tratando de um tribunal que tem expressamente como sua competência o poder-dever de interpretar o principal documento legal do ordenamento jurídico, como é o caso da CorteIDH que tem a competência expressamente prevista pela CADH de interpretá-la, não pode entender a interpretação como algo alheio a sua atividade, e nem como algo pejorativo. E mais, em se tratando de um tribunal único, ou seja, não existe qualquer outro tribunal com competência concorrente, a CorteIDH tem o dever de não só interpretar a CADH pela mera leitura, mas olhar essa convenção a partir do contexto em que ela se insere, ou seja, o contexto americano.

Zagrebelsky que entende que um tipo de interpretação ideal é aquele que leva em consideração o caráter prático da interpretação, ou seja, uma interpretação que não pode se limitar a concepções que considerem apenas o caso, ou apenas o ordenamento jurídico, visto que caso e o ordenamento jurídico são circunstâncias que devem ser consideradas conjuntamente (ZAGREBELSKY, 2005, p.131).

Sendo assim, na concepção prática do direito, a interpretação jurídica reflete a busca da norma adequada tanto para o caso como para o ordenamento. Nessa definição se põe em relevo o que Zagrebelsky chama de "caráter bipolar" da interpretação, indicando a sua tendência de conjugar ambas as vertentes (o caso e o ordenamento) fazendo-as coincidir em um resultado satisfatório. Aqui, o intérprete não está a serviço exclusivo nem do caso, nem das regras do ordenamento, manifestando assim, certa autonomia a cada um deles, fato que deriva do vínculo de dependência entre ambos (ZAGREBELSKY, 2005, p.134).

Os efeitos negativos desse método de interpretação, como os que utilizam princípios, não são anomalias, mas sim, consequências dos sistemas jurídicos atuais. A temida "explosão de subjetivismo" da interpretação é uma característica da própria sociedade pluralista atual e os 
intérpretes não podem deixar de considerar todo esse contex to em que surgem novos problemas e desafios (ZAGREBELSKY, 2005, p.140).

Desta feita, a partir do entendimento dos autores acima descritos é possível perceber que a atividade da interpretação pelos juízes é legítima, ainda mais se estivermos levando em consideração que se trata de um tribunal com a função de proteger Direitos Humanos. A interpretação, mais que legítima, é um fato que se incorporou à própria atividade jurisdicional, isto é, uma atividade que deve levar em consideração todos os parâmetros exógenos que a circundam. Uma interpretação para além do texto e pelo contexto.

Portanto, explanaremos como se dá a interpretação da CADH pelos juízes da CorteIDH através da propositura de Zagrebelsky, ou seja, a partir da análise do caso e do ordenamento jurídico conjuntamente. Nesse sentido, primeiramente, iremos analisar o ordenamento jurídico, ou seja, o Sistema Interamericano de Direitos Humanos (SIDH), para depois, analisar o(s) caso(s), ou melhor, a interpretação dada pelos juízes da CorteIDH em casos que versem sobre o direito à propriedade comunal.

\section{O SISTEMA INTERAMERICANO DE DIREITOS HUMANOS}

Para que se possa adentrar no âmbito da interpretação estabelecida pelos juízes da CorteIDH, faz-se necessário o entendimento da funcionalidade e modus operandi da tríade que sustenta o Sistema Interamericano de Direitos Humanos (SIDH): (a) Convenção Americana de Direitos Humanos (CADH); (b) Comissão Americana de Direitos Humanas (CIDH) e, por fim, (c) Corte Interamericana de Direitos Humanos (CORTEIDH). Vejamos.

A Convenção Americana de Direitos Humanos (CADH), também conhecida como Pacto de San José da Costa Rica, ao que se constata, representa o instrumento de maior relevância no que se refere ao Sistema Interamericano. O referido documento foi proposto e assinado em San José, na Costa Rica no ano de 1969, de modo que somente passou a vigorar em $1978^{3}$.

Inicialmente, cabe alertar que somente Estados-membros da Organização dos Estados Americanos (OEA) têm o direito de aderir à Convenção Americana e segundo a própria OEA, dos 35 (trinta e cinco) Estados-membros da OEA, 20 (vinte) Estados são hoje partes da Convenção Americana.

\footnotetext{
${ }^{3}$ Foi ratificada em setembro de 1997 por 25 países: Argentina, Barbados, Brasil, Bolívia, Chile, Colômbia, Costa Rica, Dominica, República Dominicana, Equador, El Salvador, Grenada, Guatemala, Haiti, Honduras, Jamaica, México, Nicarágua, Panamá, Paraguai, Peru, Suriname, Trindade e Tobago, Uruguai e Venezuela.
} 
Didaticamente, a CADH estabelece um rol de direitos humanos os quais os Estadosmembros que consignaram o pacto estão comprometidos internacionalmente a respeitar e zelar pelas garantias de cumprimento no âmbito interno de suas jurisdições e soberanias.

É a partir desta convenção que foi criada a Corte Interamericana de Direitos Humanos, definindo suas as atribuições e procedimentos tanto para a CorteIDH quanto para a Comissão Interamericana de Direitos Humanos. Esta última possui sua sede em Washington D.C. e foi criada pela OEA em 1959 e, em forma conjunta com a CorteIDH, instalada em 1979, configurando-se como uma instituição de extrema relevância no Sistema Interamericano. Conforme relata Flávia Piovesan, a propósito da Convenção:

Promover a observância e a proteção dos direitos humanos na América é a principal função da Comissão Interamericana. Para tanto, cabe à Comissão: fazer recomendações aos governos dos Estados-partes prevendo a adoção de medidas adequadas à proteção destes direitos; preparar estudos e relatórios que se mostrem necessários; requisitar aos governos informações relativas às medidas por eles adotadas concernentes à efetiva aplicação da Convenção; submeter um relatório anual à assembléia Geral da Organização dos Estados Americanos. (PIOVESAN, 2000, p.34).

Compete à $\mathrm{CIDH}$ examinar as petições encaminhadas por indivíduo ou grupos de indivíduos, ou ainda entidades não-governamentais, que contenham denúncia de violação a direito consagrado pela Convenção por Estado que dela seja parte. Importante saber, o Estado, ao se tornar parte da Convenção, aceita automática e obrigatoriamente a competência da Comissão para examinar petições individuais, não sendo necessário a elaboração de qualquer declaração expressa e específica para este fim.

Relevante lembrar que a CIDH mantém poderes adicionais que não decorrem diretamente da Convenção, dentre eles, o de processar petições individuais no que se referir a casos de Estados não-signatários da mesma.

Além disso, a CIDH está encarregada de decidir sobre a admissibilidade das petições encaminhadas a ela, tendo como consideração os requisitos expostos neste dispositivo. Havendo juízo de admissibilidade, a Comissão solicita informações ao Governo denunciado. Após o recebimento do relatório sobre as acusações, o Estado possui o prazo de até 03 (três) meses para conferir cumprimento às recomendações (resolução do caso entre as partes, por exemplo), em caso de efetivo descumprimento violador de direitos humanos, ou, então, até mesmo ser submetido à Corte Interamericana.

Sendo assim, no prazo de 03 (três) meses o caso poderá ser encaminhado ao órgão jurisdicional do sistema regional interamericano, a Corte Interamericana de Direitos Humanos - localizada em San José, na Costa Rica -, podendo tão apenas fazer o encaminhamento 
(espécie de “denúncia”) à Comissão Interamericana e os Estados-partes. Gorenstein, esclarece sobre a Corte:

A Corte Interamericana de Direitos Humanos é o órgão jurisdicional do sistema por excelência. Enquanto os membros da Comissão são chamados de Comissários, os membros da Corte detêm o título de juízes; enquanto a Comissão elabora um relatório final com "recomendações", a Corte emite uma sentença "definitiva e inapelável", nas palavras da Convenção Americana. As sentenças da Corte são, ainda, obrigatórias, não podendo os Estados recusarse a cumpri-las. (GORESTEIN, 2002, p.95).

A CorteIDH se diferencia da CIDH por dois principais motivos: (1) o primeiro consiste na sua função contenciosa, ou seja, é o órgão julgador do SIDH que ao verificar a violação de direitos humanos e comprovar sua competência em razão das partes, do objeto da denúncia e do tempo, pode responsabilizar internacionalmente aquele Estado que ratificou e reconheceu sua jurisdição; já o (2) segundo motivo, consiste na sua função consultiva, pois o único órgão competente para interpretar a CADH e emitir pareceres, ou melhor, opiniões consultivas com efeito vinculante é a CorteIDH.

Neste contexto, a República Federativa do Brasil foi um dos Estados que mais tardiamente aderiram à Convenção, fazendo-o apenas em 25 de setembro de 1992. Tendo reconhecido a competência obrigatória da CorteIDH em todos os casos relativos à interpretação ou aplicação da CADH - por intermédio do Decreto Legislativo n. 89, de 03 de dezembro de 1998 -, desde que os fatos ocorram a partir da vigência da referida figura legal, de acordo com o que prescreve o instrumento internacional.

Neste sentido com matriz didática, a partir das noções básicas dos principais mecanismos de operação do Sistema Interamericano de Direitos Humanos - com delineamentos básicos da $\mathrm{CADH}, \mathrm{CIDH}$ e CorteIDH -, cabe a seguir verificar os elementos teóricos da interpretação dos juízes da CorteIDH em casos que verse sobre o direito à propriedade comunal e qual a sua importância em um contexto como esse.

\section{A INTERPRETAÇÃO DO DIREITO À PROPRIEDADE COMUNAL PELA CORTEIDH}

A Convenção Americana não possui em seu texto nenhum direito de cunho ambiental, já o Protocolo de San Salvador que é um protocolo adicional à CADH sobre Direitos Econômicos, sociais e culturais (DESC), e que somente pode ser invocado nos termos do artigo 19, limitando-se a casos de organização sindical e acesso à educação, inseriu em seu artigo 11 
o direito de viver em um ambiente sadio e o dever estatal de promover a proteção, preservação e melhoramento do meio ambiente (MAZZUOLI e TEIXEIRA, 2013, p.211).

Aliás, "os tratados interamericanos não contém nenhuma especificidade cultural devido a influência liberal no marco jurídico americano" herança também do pensamento eurocêntrico que considera os povos tradicionais em si como um problema (ESTUPINAN SILVA, 2014, p.317), na medida em que "povos indígenas e quilombolas bem como as demais comunidades tradicionais (...) são vistos como sujeitos biologizados, isto é, como mera extensão dos recursos naturais, sem consciência e sem direitos" (ALMEIDA, 2010, p.95).

Nesse sentido, da simples leitura do artigo 21 é possível constatar que a CADH não menciona expressamente "propriedade indígena" ou "propriedade comunal" ou "territorialidade", pois tal artigo somente faz uma abordagem genérica acerca do direito de propriedade.

Entretanto, por se tratar de Povo Tradicional, tal artigo deve ser analisado para além do texto, tendo em vista que por possuírem uma relação ímpar com seu território, a propriedade ultrapassa o cunho meramente pecuniário, por constituir parte integrante da identidade do povo tradicional.

Daí porque, mesmo que expressamente previsto na $\mathrm{CADH}$ como direito à propriedade privada, tal artigo, ao ser aplicado em um contexto de violação de terras tradicionalmente ocupadas, exige uma proteção jurídica ainda mais qualificada (MARTÍNEZ DE BRINGAS, 2008, p.28), tendo em vista que terras tradicionalmente ocupadas expressam uma diversidade de formas de existência coletiva de diferentes povos e grupos sociais em suas relações com os recursos da natureza (ALMEIDA, 2012), a territorialidade funciona como fator de identificação, defesa e força, mesmo em se tratando de apropriações temporárias dos recursos naturais como grupos sociais classificados muitas vezes como "nômades" e "itinerantes", pois essas formas de apropriação dos recursos possuem um caráter dinâmico (ALMEIDA, 2006, p. 03).

A territorialidade pode ser entendida ainda como "homeland", pois além de ser um produto histórico de processos sociais e políticos, constitui uma multiplicidade de expressões, daí porque, faz-se mister análises etnográficas para entender as formas específicas de diversidade de territórios e o entendimento do conceito de cosmografia que é definido como "saberes ambientais, ideologias e identidades que um grupo social utiliza para estabelecer e manter seu território" (LITTLE, 2002, p.03).

Por isso, em que pese o direito à territorialidade ser ausente na $\mathrm{CADH}$, este direito já vem sido tratado pela Convenção 169 da OIT em seu artigo 13, motivo que ensejou o 
posicionamento da CorteIDH no sentido de aplicar o artigo 21 da Convenção, “(...) à luz do contexto próprio das comunidades tradicionais, bem como de outras normas internacionais, como a Convenção 169 da OIT - como direito comunal ou coletivo dos povos e comunidades indígenas" (AIDA, 2010, p.88).

Isto é, apesar da CorteIDH não utilizar o termo "direito à territorialidade" e ao invés disso, utilizar o termo "propriedade comunal", o entendimento proposto pelo tribunal é de que o conceito de propriedade disposto na $\mathrm{CADH}$ é amplo, abarcando como bens as coisas apropriáveis, assim como todo direito e interesse integrantes do patrimônio de uma pessoa, ou seja, a CorteIDH entende que o artigo 21 da CADH protege a propriedade em um sentido que compreende, entre outros, o direito dos membros das comunidades indígenas no quadro da propriedade comunal (CORTEIDH, CASO MAYAGNA VS. NICARÁGUA, 2001, p.148).

Logo, a propriedade comunal deve ser considerada de maneira autônoma e não restritiva, devendo-se valer de todos os instrumentos legais a sua disposição para garantir a proteção das mencionadas comunidades, tendo em vista os prejuízos sociais, ambientais e econômicos que elas vêm enfrentando (CORTEIDH, CASO MOIWANA VS. SURINAME, 2005).

Nesse sentido, resta claro que a CorteIDH vem realizando uma interpretação evolutiva, tendo em vista que rompe com a visão que encara a propriedade como um direito eminentemente individual, para proporcionar um alcance em conformidade com os direitos humanos, ou seja, "que engloba a diversidade de modos de vida válidos e dignos de proteção e garantia" (MELO, 2006, p.36).

Para ampliar a interpretação do direito à propriedade, a CorteIDH fez uso de dois métodos de interpretação: (1) método dinâmico de interpretação, que consiste na interpretação do direito aplicado em um contexto e relação estreita com a realidade do peticionário; e do (2) método multicultural de interpretação, que propicia uma análise multicultural da perspectiva universal dos direitos humanos (ESTUPIÑAN SILVA, 2014, p.319).

Sendo tais métodos utilizados através da técnica de interpretação chamada de valorização da abertura normativa identificada por Laurence Burgorgue-Larsen, a qual referese à interpretação "aberta" da CADH que propicia uma ampliação do conteúdo dos direitos. Segundo a autora, isto encontra previsão no artigo 29 da CADH que ao primar pelo Princípio Pró-homine permite que a CorteIDH a recorra às diversas fontes do direito internacional para interpretar a $\mathrm{CADH}$, transformando a $\mathrm{CADH}$ em um "instrumento vivo", pois quando esse tribunal utiliza outros documentos para interpretar a $\mathrm{CADH}$, ela reposiciona a Convenção não 
somente como o "corpus iuris interamericano", mas também como um "corpo iuris internacional" (BURGORGUE-LARSEN, 2014, p.120).

Essa abertura a diversas fontes exteriores tem por objetivo principal interpretar tanto o conteúdo como o alcance dos direitos garantidos pela $\mathrm{CADH}$, tendo em vista que identificar o alcance de um direito se caracteriza por levar em consideração certos contextos específicos do continente latino-americano, bem como a ideia de eficácia, pois a CorteIDH, conforme ressalta Laurence Burgorgue-Larsen, fará todo o possível para que os direitos consagrados no texto do tratado tenham um alcance concreto e efetivo (BURGORGUE-LARSEN, 2014, p.121), além de proporcionar a reinterpretação das obrigações positivas multiculturais inerentes, é o método que atualmente é o predominante na jurisprudência da CorteIDH (BURGORGUE-LARSEN, 2014, p.333).

$\mathrm{O}$ direito à propriedade é reinterpretado a partir de uma perspectiva dinâmica e multicultural da CADH e é aqui que a interpretação evolutiva fica mais evidente, pois esse tipo de interpretação "permite abordar os tratados de direitos humanos como 'instrumentos vivos' cuja interpretação deve acompanhar a evolução dos tempos e as condições de vida atuais" (MAUÉS, 2007, p.128).

O primeiro caso em que a CorteIDH demonstrou esse posicionamento foi no do Povo Mayagna (Sumo) Awas Tingni em uma demanda contra a Nicarágua, em 2001. A sentença deste caso representa um verdadeiro marco na trajetória da litigância dos Povos Tradicionais no SIDH, por ser a primeira de uma série de sentenças sobre o direito à territorialidade institucionalizado através da criação jurisprudencial do instituto da propriedade comunal.

Outro importante exemplo de litigância foi o caso do Povo Indígena Yakye Axa em uma lide contra o Paraguai, em 2005, por consolidar a vinculação da aplicação da CADH com a Convenção 169 da OIT em um contexto envolvendo Povos Indígenas e por ampliar o conteúdo do direito à propriedade comunal.

Tais casos proporcionaram o entendimento de que estes Povos possuem o direito à demarcação e concessão de títulos oficiais das terras que tradicionalmente ocupam (PASQUALUCCI, 2009, p.64), ampliando assim as obrigações estatais, bem como as distintas reparações impostas aos Estados, que, por terem uma perspectiva integral, e não só patrimonial, visam assegurar a justiça, a reabilitação do território, a satisfação dos outros direitos violados e o reconhecimento público da responsabilidade internacional (GAMBOA, 2013, p.50).

Desses casos, destacamos aqui as quatro principais características que a interpretação evolutiva da propriedade comunal realizada pela CorteIDH congloba. 
A (1) primeira característica, refere-se ao caráter coletivo da propriedade comunal que é considerado como um princípio hermenêutico que permite a compreensão de culturas diferenciadas, com sujeitos distintos e em situações geopolíticas variadas, dessa forma, o artigo 21 da CADH não se refere somente à concepção civilista de propriedade, "mas também pode (e deve) ser interpretado, de tal forma, que a propriedade comunal da terra e dos recursos naturais sejam protegidos" (CHIRIBOGA, 2006, p.60).

Já a (2) segunda característica, refere-se à origem consuetudinária do direito de propriedade comunal que prevalece sobre o direito à propriedade privada, pois a noção de tradicional e de originário não se reduz ao tempo em que residiam ou ao título e demarcação do território, pois o sentido que tal característica propõe é a noção de pertencimento que se reflete nos vínculos simbólicos e nos valores que o território representa.

No que tange a (3) terceira característica, está relacionada com a especial relação dos povos tradicionais com suas terras e territórios que proporciona a interconexão da propriedade comunal com os DESC, na medida em que a CorteIDH tem protegido direitos sociais a partir da proteção dos direitos civis e políticos (PARRA VERA, 2008, p.30), como é o caso do projeto de vida que reflete a liberdade de cada pessoa para realizar sua vida e gozar de seu bem estar (PARRA VERA, 2012, p.278), ou seja, tal entendimento fomenta a compreensão de território como base material e espiritual dos DESC dos povos tradicionais demonstrando que tais direitos podem “ser suscetíveis de proteção por via da justiça internacional” (MELO, 2006, p.36).

E por fim, a (4) quarta característica refere-se aos deveres estatais de proteção à propriedade comunal, que transcende a compreensão reducionista de garantias jurídicas, institucionais e legais para implicar numa nova relação de direitos e deveres, e consequentemente, numa nova consideração da subjetividade das vítimas e na reformulação dos deveres públicos do Estado a fim de garantir os direitos fundamentais dos povos tradicionais no plano interno (e prático) (MARTÍNEZ DE BRINGAS, 2008, p.19).

\section{ENTENDENDO A INTERPRETAÇÃO}

Conforme ensinado por Zagrebelsky, a interpretação deve levar em consideração, o caso e o ordenamento jurídico conjuntamente. Nesse sentido, após traçarmos o entendimento do SIDH e como essa interpretação foi desenvolvida nos casos que versem sobre propriedade comunal, insta agora, para a melhor compreensão desse fenômeno, em que a CorteIDH interpreta o texto da CADH de maneira construtiva, examinar o contexto em que ela está 
inserida, isto é: o (I) contexto jurídico; (II) político e (III) sociológico - para demonstrar as razões que levaram a CorteIDH a privilegiar de maneira regular, quando não sistemática, a interpretação extensiva da CADH e mais protetora dos Direitos Humanos. Vejamos.

No (I) contexto jurídico, o artigo 29 da CADH exerce uma função primordial, pois tal artigo trata sobre um tipo de interpretação que tenha como fundamento e diretriz o Princípio Pró-homine, ou seja, uma interpretação que conceda aos indivíduos uma proteção máxima é aquela que seja mais favorável aos Direitos Humanos.

Nesse sentido, por objetivar uma interpretação pró-homine é que a CorteIDH vem privilegiando o uso do método teleológico de interpretação - mencionado expressamente no artigo 31.1 da Convenção de Viena -, em detrimento dos outros métodos (textual, histórico e sistemático), nos famosos casos paradigmáticos ou hard cases.

Ao lado do artigo 29 da CADH que propicia esse tribunal a se utilizar desse método, encontra-se o alcance da competência ratione materiae da Corte IDH, pois a partir do momento em que um Estado ratifica a $\mathrm{CADH}$, pode a CorteIDH aplicar aos fatos relevantes do caso, fontes distintas da própria convenção, como outros documentos e tratados internacionais (BURGORGUE-LARSEN, 2014, p.109).

Além disso, a CorteIDH também se utiliza dessa prática em outros casos, ou seja, se são conceitos provenientes de diferentes tipos de instrumentos internacionais e são efetivamente aplicados em casos em que os Estados ratificaram as respectivas convenções, eles também são utilizados com fins de interpretação em outros casos, o que Burgorgue-Larsen identifica como um "fenômeno de migração (interconvencional)" que entende que a interpretação mais protetora ao conjunto de Estados-Parte da $\mathrm{CADH}$, inclui os Estados que não ratificaram tais tradados específicos (BURGORGUE-LARSEN, 2014, p.109).

No que tange ao (II) contexto político, destaca-se a violência inerente à história do continente latino-americano, marcada por guerrilhas, guerras civis, terrorismo dos Estados e os danos causados pela política dos Estados Unidos da América que por objetivar conter o "expansionismo roxo" promoveu a extensão da Doutrina da Segurança Nacional (BURGORGUE-LARSEN, 2014, p.109).

Nesse contexto, relevante foi o papel dos organismos do Sistema Interamericano de Direitos Humanos, em especial, o pioneirismo da Comissão Interamericana de Direitos Humanos e seu protagonismo no combate às atrocidades perpetradas pelos golpes de Estados, que propiciavam violações massivas de Direitos Humanos, através da publicação dos seus relatórios realizados sobre a situação dos Direitos Humanos e suas visitas in loco aos Estados Membros que reafirmaram sua autoridade e legitimidade. 
Outro fator relevante foi a criação da própria CorteIDH, tendo em vista que a institucionalização desse tribunal justifica a utilização de métodos que favoreçam a interpretação mais favorável e que, ao mesmo tempo, restrinja as possibilidades de suspender certos direitos diante das práticas estatais de instrumentalizar a noção de medidas de exceção. Ou seja, traz a CorteIDH em suas interpretações, um enfoque realista da proteção dos Direitos Humanos.

O (III) contexto sociológico analisa a composição da CorteIDH, tendo em vista que descobrir os membros que compõe, ou já compuseram esse tribunal, é um meio subsidiário para compreender a valorização das técnicas de interpretação que favorecem a proteção mais ampla dos Direitos Humanos.

Daí porque, ressaltamos dois fatores de influência sobre os juízes, a saber: os elementos estritamente técnicos, ou seja, a formação dos juízes (acadêmicos ou profissionais) e suas especialidades (direito internacional e/ou outras disciplinas), pois a CorteIDH não tem sido integrada exclusivamente por especialistas em direito internacional - daí a importância de conhecer as produções acadêmicas e as atividades (passadas ou presentes) dos juízes -; e o outro elemento refere-se à posição doutrinal, isto é, clássica ou ativista, pois essas opções doutrinárias podem ter uma importância decisiva diante da composição do colegiado de juízes desta Corte que é formada por 07 (sete) juízes eleitos por um mandato de 06 (seis) anos, renováveis por uma só vez, que trabalham com o apoio de jovens advogados dedicados a causa dos Direitos Humanos.

Desta forma, instaurado tal contexto que justifica as razões para que a CorteIDH adote um método interpretativo e evolutivo, resta claro que esse tribunal realiza mais que uma interpretação conforme o caso e ordenamento jurídico, simultaneamente, como ensinou Zagrebelsky, por interpretar de maneira coerente com a sua função de proteger direitos que não podem ser restringidos pelo texto, pois são direitos vivos; humanos; em transformação e em construção; Ou seja, a interpretação aqui está incorporada no exercício das atividades dos juízes da CorteIDH, que além de constituir um dever sinequanon de um tribunal protetor de Direitos Humanos, reforça a importância da atuação desse tribunal em uma região marcada pela violação de Direitos Humanos. 


\section{CONSIDERAÇÕES FINAIS}

O objetivo a que este trabalho se propôs foi o de analisar a interpretação utilizada pelos juízes da Corte Interamericana de Direitos Humanos em sentença de casos que versem sobre propriedade comunal.

Com esta meta-trabalho, após metodologicamente dimensionar este estudo a partir de tópicos elucidativos sobre (1) uma suma teórico-procedimental sobre o direito e interpretação; (2) uma análise pragmática acerca do funcionamento do SIDH; (3) comentários a respeito da interpretação da CorteIDH em casos sobre propriedade comunal; e (4) uma análise sobre o contexto em que essa interpretação está inserida, nos levou a concluir (4) que a interpretação da CorteIDH entendida como evolutiva e construtiva dos Direitos Humanos é coerente com o entendimento de Zagrebelsky sobre o que é interpretação, e com a sua função de corte que protege direitos das pessoas e não de instituições.

O âmago desta pesquisa científica se encontra(ou), portanto, no olhar de importância que se deve dar à tentativa, cada vez maior, de estudar cada vez mais a interpretação que seja condizente com a proteção dos Direitos Humanos, ou seja uma interpretação para além do texto.

Em suma, a conclusão deste trabalho não tem por finalidade esgotar o debate e nem todas as questões pertinentes que a análise da interpretação da $\mathrm{CADH}$ estabelecida pelos juízes da CorteIDH levanta. Dada a abrangência, novidade e escassez doutrinária a respeito da mesma, tal esgotamento extrapolaria os limites inerentes a um artigo científico. Porém, naquilo que se entendeu essencial, procurou-se conferir a completude e objetividade necessárias ao desfecho sustentável deste ensaio.

\section{REFERÊNCIAS BIBLIOGRÁFICAS}

AIDA. Guia de Defesa Ambiental: Construindo a Estratégia para o Litígio de Casos diante do Sistema Interamericano de Direitos Humanos. 2010.

ALMEIDA, Alfredo Wagner Berno de. Direitos territoriais e étnicos: As estratégias dos agronegócios na Amazônia. In ZHOURI, Andréa; LASCHEFSKI, Klemens (org.). Desenvolvimento e conflitos ambientais. Belo Horizonte: Editora UFMG, 2010.

. Terras tradicionalmente ocupadas. In SOUZA LIMA, Antonio Carlos (Coord). Antropologia \& Direito: temas antropológicos para estudos jurídicos. Brasília/Rio de Janeiro, Contra Capa/ LACED/ABA, 2012. 
Terras de quilombo, terras indígenas, babaçuais livres, castanhais do povo, faxinais e fundos de pasto: terras tradicionalmente ocupadas. Manaus: PPGSA-UFAM, 2006.

BURGORGUE-LARSEN, Laurence. El contexto, las técnicas y las consecuencias de la interpretação de la Convención Americana de los Derechos Humanos. Estudios Constitucionales, a. 12, n. 1, 2014.

CHIRIBOGA, Oswaldo Ruiz. O direito à identidade cultural dos povos indígenas e das minorias nacionais: um olhar a partir do sistema interamericano. SUR. Revista Internacional de Direitos Humanos. Nº5, ano 3, 2006, p.60.

CORTE IDH. Caso Comunidade Mayagna (Sumo) Awas Tingni vs Nicarágua. Sentença de 31 de agosto de 2001. 2005 .

.Caso da Comunidade Indígena Yakye Axa vs. Paraguai. Sentença 17 de Junho de .Caso da Comunidade Moiwana vs. Suriname. Sentença de 15 de junho de 2005.

.Caso Salvador Chiriboga vs. Equador. Sentença de 06 de maio de 2008.

2007.

.Caso Chaparro Álvarez y Lapo Íñiguez vs. Equador. Sentença 21 de novembro de

.Caso do Povo Saramaka vs. Suriname. Sentença de 28 de novembro de 2007.

ESTUPINAN SILVA, Rosmerlin; IBÁÑEZ RIVAS, Juana María. La jurisprudência de la Corte Interamericana de Derechos Humanos en matéria de pueblos indígenas y tribales". In BELTRÃO, Jane Felipe; BRITO FILHO, José Claudio Monteiro de; GÓMEZ, Itziar; PAJARES, Emilio; PAREDES, Felipe; ZÚÑINGA, Yanira (Coords.). Derechos humanos de los grupos vulnerables. Manual. DHES, Red de Derechos Humanos y Educación Superior. 2014.

GAMBOA, Jorge F. Calderon. La evolución de la "reparación integral" en la jurisprudencia de la Corte Interamericana de Derechos Humanos. México: Comisión Nacional de los Derechos Humanos, 2013.

GORENSTEIN, Fabiana. O Sistema Interamericano de Proteção dos Direitos Humanos. In LIMA JR., Jayme Benvenuto. Manual de Direitos Humanos Internacionais: Acesso aos Sistemas Global e Regional de Proteção dos Direitos Humanos. São Paulo: Loyola, 2002.

KAUFMANN, Arthur. Filosofia do direito. Lisboa: Fundação Calouste Gulbenkian, 2004. LITTLE. Paul E. Territórios Sociais e Povos Tradicionais no Brasil: por uma antropologia da territorialidade. Série Antropologia. Brasília. 2002. Disponível em: <http://www.direito.mppr.mp.br/arquivos/File/PaulLittle.pdf>. Acesso em: 02/07/2014.

MARTÍNEZ DE BRINGAS, Asier. La deconstrucción del concepto de propriedad. Una aproximacíon intercultural a los derechos territoriales indígenas. Utopía y práxis latinoamericana. Revista Internacional de Filosofía Iberoamericana y Teoría Social. Ano 14, $\mathrm{n}^{\circ}$ 45. Venezuela. 2009. 
MAUÉS, Antonio Moreira. O direito à vida na jurisprudência da Corte Interamericana de Direitos Humanos. In MINISTÉRIO PÚBLICO DO ESTADO DO PARÁ. Revista do Ministério Público do Estado do Pará. Centro de Estudos e Aperfeiçoamento Funcional. Ano 2, Volume 2. Belém: AVISI - Agência de Comunicação Ltda, 2007.

MAZZUOLI, Valerio de Oliveira; TEIXEIRA, Gustavo de Faria Moreira. O direito internacional do meio ambiente e o greening da Convenção Americana sobre Direitos Humanos. Revista Direito GV, nº 17, jan./jun. 2013.

MELO, Mario. Últimos avanços na justiciabilidade dos direitos indígenas no Sistema Interamericano de Direitos Humanos. SUR. Revista Internacional de Direitos Humanos, $\mathrm{n}^{\circ} 04$, ano 03. 2006.

MOORE, Michael S. Interpretando a interpretação. In MARMOR, Andrei. Direito e interpretação. São Paulo: Martins Fontes, 2004.

PARRA VERA, Oscar. Derechos humanos y pobreza en el sistema interamericano. Revista IIDH, nº 56, dez./dic. 2012.

; VILLANUEVA HERMIDA, María Aránzazu; MARTIN, Agustín Enrique. Introducción: los derechos sociales y el enfoque de derechos humanos en las estrategias de desarrollo y erradicación de la pobreza. In INSTITUTO INTERAMERICANO DE DERECHOS HUMANOS. Protección internacional de los derechos económicos, sociales y culturales. Sistema universal y sistema interamericano. San José, IIDH, 2008.

PASQUALUCCI, Jo M. International Indigenous Land Rights: a critique of the jurisprudence of the American Court of Human Rights in light of the United Nations Declaration on the Rights of Indigenous People. Wisconsin International Law Journal. Vol. 27, nº. 01, 2009.

PIOVESAN, Flávia. Introdução ao Sistema Interamericano de Proteção dos Direitos Humanos: a Convenção Americana de Direitos Humanos. In GOMES, Luiz Flávio e PIOVESAN, Flávia. O Sistema Interamericano de Proteção dos Direitos Humanos e o Direito Brasileiro. São Paulo: Revista dos Tribunais, 2000.

ZAGREBELSKY, Gustavo. El derecho dúctil: ley, derechos, justicia. In TROTTA, Los jueces y el derecho, Madri, 2005. 